\title{
Compassion at Work
}

\author{
Jane E. Dutton \\ University of Michigan \\ Kristina M. Workman \\ Cornell University \\ Ashley E. Hardin \\ University of Michigan
}

\begin{abstract}
Compassion is an interpersonal process involving the noticing, feeling, sense making, and acting that alleviates the suffering of another person. This process has recently received substantial attention by organizational researchers and practitioners alike. This article reviews what researchers currently know about compassion as it unfolds in dyadic interactions in work organizations. We begin by reviewing what we know about the benefits of compassion for the person who is suffering, for the provider of compassion, and for third parties who witness or hear about compassion at work. The heart of the article focuses on what research tells us about embedding compassion in the personal, relational, and organizational contexts in which compassion takes place. We conclude by discussing implications for practice and for the future research agenda regarding this vital interpersonal process.
\end{abstract}

\section{INTRODUCTION}

Organizations are emotional arenas (Fineman 2000). Whether due to events in one's personal life or organizationally induced, human suffering within organizations is inevitable. When that suffering is met with concern and caring responses, compassion occurs, and that is the focus of our review. We survey what we know about the interpersonal process of compassion at work and expose theoretical and empirical terrains that demand development and new insights. We examine both empirical and theoretical treatments of compassion in work organizations as well as insights about this process from studies in psychology in which compassion is portrayed mostly as a feeling state (e.g., Goetz et al. 2010). By contrast, we conceptualize compassion as an interpersonal process in which both the sufferer and the focal actor ${ }^{1}$ play a role in how a particular episode unfolds over time. Our contribution is twofold. First, we integrate the research to date by modeling compassion at work as a dynamic interpersonal process or set of sub processes (Kanov et al. 2004) involving two or more individuals that is activated through the noticing of human suffering. Second, we model this interpersonal process as unfolding at three levels of context-personal, relational, and organizational. Thus, our review reveals the deeply situated nature of compassion and therefore the outcomes that result.

We preface our review by explaining why there is a need to highlight research on compassion at work and why now is the time to do so. We then describe the breadth of different forms of suffering at

\footnotetext{
${ }^{1}$ We have intentionally labeled the two parties involved in compassion episodes as focal actor and sufferer, as opposed to givers and receivers, to avoid invoking a purely social-exchange mindset or logic. Also, although we acknowledge that compassion can sometimes involve multiple people suffering and multiple people responding at the same time, for analytic purposes, we focus on a compassion episode involving two people.
} 
work, the difference that compassion makes in organizations, and the core compassion sub-processes. Our review reveals the patterning of compassion by showing the contextual embedding of the compassion process in roles (personal context), features of the relationship (relational context), and characteristics of the organization (organizational context) that affect its unfolding. We also review what we know about how personal characteristics affect the process. For organizational psychologists, understanding the patterning of compassion at work opens new research inquiries about a crucial interpersonal process that is in its infancy in terms of depth and breadth of empirical research. At the same time, a focus on compassion reinfuses accounts of interpersonal relationships at work with the humanity that many scholars have noted is often missing (Adler \& Hansen 2012, Dutton 2003, Tsui 2013), reminding us of what matters most in organizations (Whetten 2001).

A focus on compassion at work is both timeless and timely (Rynes et al. 2012, Tsui 2013). Its timelessness arises from compassion's centrality to religious and philosophical teachings over centuries that have debated, yet for the most part affirmed, its importance for the human condition (Nussbaum 1996). The timeliness of a focus on compassion at work arises from new scientific evidence and recent calls for more enriched relational perspectives in organizational psychology. Social scientists have revealed basic human drives and interests to be as other-serving as they are self-serving (e.g., Brown et al. 2011). In addition, depictions of our own species (Keltner 2009) and related species (De Waal 2009) as born to be kind, empathic, and cooperative affirm this alternative view of humans' basic motivations. These depictions serve as a corrective to views that humans conduct themselves in a predominantly selfinterested manner, suggesting that compassion is a normal and pervasive way of interrelating at work (and beyond) and thus central rather than peripheral to understanding human experience. The model of compassion at work that we present takes seriously the embedding of this interpersonal process in the personal, relational, and organizational contexts and provides new windows into how this other-serving behavior unfolds in complex social situations.

A focus on compassion at work also fits with the growing focus on relational perspectives in work (e.g., Dutton 8c Ragins 2007) that take seriously the centrality of relationships and the role they play in how works gets done (e.g., Gittell 8c Douglass 2012) and in employees' identity and well-being (e.g., Gersick et al. 2000; Kahn 1993,1998). Recent reviews of how coworkers matter (Chiaburu 8c Harrison 2008) and the underlying dimensions of relationships at work (Ferris et al. 2009) attest to the importance of understanding interpersonal dynamics and outcomes in organizations. A focus on interpersonal compassion at work highlights the role of other people in acknowledging and responding to real, pervasive, and consequential suffering at work (Frost 2003).

\section{THE BREADTH OF SUFFERING AT WORK}

Suffering is triggered by an event or circumstance that is experienced as disruptive or threatening and that therefore causes a state of distress, which may include physical and emotional pain, trauma, existential anguish, concerns about the future, and feelings of disconnection (Cassell 1999, Lilius et al. 2012). The experience is deeply personal, meaning that even if two people encounter the same difficult situation, whether, why, and how they suffer are likely to be unique (Cassell 1999).

Suffering at work may arise from events in an individual's personal life. One of the most common forms of suffering is grief, "a process that includes the emotional, physical and social responses to a major loss, most commonly the death of a loved one" (Hazen 2008, p. 79). Grief often complicates the accomplishment of work tasks for sufferers by causing "mental lapses, decreased energy, difficulty 
in making decisions, anxiety, helplessness, inability to concentrate, preoccupation, social withdrawal, memory gaps, crying, and other seemingly inappropriate (to the work environment) emotional responses" (Stein 8c Winokuer 1989, p. 98). In addition to grief, other personal issues such as the dissolution of romantic relationships (Manns 8c Little 2011), mental or physical illness of oneself or a loved one, financial difficulties, or other family issues (Lilius et al. 2008) may distress, distract, or otherwise strain individuals while they are at work.

Suffering at work may also arise from work itself. Worline 8c Boik (2006) describe work as composed of the emotional highs and lows of being a person, and Driver (2007) details ways in which the lows may be painful experiences that arise when individuals' emotions, desires, and needs collide and conflict with organizational realities. Individuals may experience job stress, a particular form of suffering that is commonly discussed in the organizational literature, as a consequence of status incongruence (i.e., working in a pay grade that is either higher or lower than would be commensurate with one's job experience; Erickson et al. 1972), lack of job security (Ashford et al. 1989), or even the accumulation of minor everyday hassles (Chamberlain 8c Zika 1990). After a prolonged period of stress, suffering in the form of burnout may occur as a result of inadequate control over one's work, frustrated hopes and expectations, or the feeling of losing meaning (lacovides et al. 2003). Work-family conflict may also be a source of significant distress (Rice et al. 1992).

Negative interpersonal experiences at work can be challenging. Workplaces are increasingly hostile environments, and "persistent, offensive, abusive, intimidating, malicious, or insulting behaviors" are on the rise (Lee 2000, p. 593). Dealing with toxic bosses and colleagues (Frost 8c Robinson 1999), participating in corrosive politics (e.g., Williams 8c Dutton 1999), and being involved in serious forms of negative interpersonal encounters such as sexual harassment, vandalism, psychological abuse, and workplace violence (Johnson 8c Indvik 1996, Stewart 8c Kleiner 1997) may all evoke suffering.

Organizational actions may also trigger suffering. Downsizing unsettles people who lose their jobs and distresses survivors who are concerned about their colleagues' losses along with their own job security (Mishra et al. 2009). Even well-intentioned organizational programs can backfire and become sources of suffering for workers (Driver 2007). For example, individuals may feel betrayed if initiatives designed to create more positive, humane workplaces are nothing more than rhetoric (Victor \& Stephens 1994) or if initiatives meant to foster high performance and continuous learning create extra stress (Driver 2007).

Clearly, suffering is pervasive in the workplace. Statistics on grief, stress, and burnout at work reveal that suffering is also costly. According to the Grief Recovery Institute, firms lose more than \$75 billion annually due to employees dealing with grief (Zaslow 2002). Estimates of job-stress- related losses are even greater at $\$ 300$ billion a year; these losses stem from absenteeism, turnover, diminished productivity, and medical, legal, and insurance costs (Rosch 2001). Financial cost estimates do not do justice to the emotional and physical costs of human pain. By understanding the benefits of compassion, we begin to appreciate how this form of interpersonal caring reduces the costs of suffering while providing other gains as well.

\section{The Difference Compassion at Work Makes}

Although the moral and financial motivation to reduce suffering at work is compelling in its own right, the case for synthesizing and furthering the study of compassion becomes even stronger when we 
consider the range of ways that compassion matters at work. Research suggests that interpersonal compassion has the potential to impact not only sufferers but also focal actors, third parties, and organizations. Understanding the many forms and avenues of compassion's impact underscores the need to continue learning about how compassion unfolds as well as what hinders or facilitates it.

Most empirical research examines how compassion benefits sufferers. Compassion heals, allowing people to recover physically from illness and bodily harm (Brody 1992) and psychologically from grief (Bento 1994, Doka 1989). Also, evidence suggests that compassion in the workplace calls up positive emotions (e.g., gratitude), reduces anxiety (Lilius et al. 2008), and increases a sufferer's attachment and commitment to the organization (Grant et al. 2008, Lilius et al. 2008). At the same time, empirical studies suggest that compassion communicates dignity and worth from one person to another, helping people at work feel valued (Clark 1987, Dutton et al. 2012, Frost 2003, Frost et al. 2000). This sense of being valued and worthy is not a state that is a given in work organizations; rather, it is something that is created or destroyed by the way that people interact with one another at work (Dutton et al. 2012).

Compassion from another person shapes a sufferer's sense making about oneself (e.g., seeing the self as more capable), one's peers (e.g., viewing one's peers as more humane), and one's organization (e.g., seeing the organization as caring), in all cases changing interpretations to be more positive (Lilius et al. 2008). (For details about sense making, see Focal Actor and Sufferer Engaging in Sense making, below.) Instrumentally, compassion often involves the provision of resources (e.g., time, concern, material goods) that can help people resolve or cope with the sources of their suffering and recover the ability to carry on with their lives (Dutton et al. 2006) and resume some sense of normalcy at work (Powley 2009). At the same time, compassion from others is particularly important for preventing or reducing compassion fatigue if one has a caregiving job (Kahn 1993) or if one routinely deals with suffering clients or coworkers (e.g., O’Donohoe \& Turley 2006).

The literature to date has also described several notable effects of compassion on the person demonstrating it. Negative consequences for focal actors who attempt to engage in too much compassionate responding may experience compassion fatigue (e.g., Figley 1995), moral distress from being unable to do what is right and unable to adequately relieve others' suffering, or secondary trauma or dysfunction from prolonged exposure to others' suffering (Halifax 2011). However, being compassionate may also have beneficial effects on focal actors. Responding compassionately at work can lead to greater compassion satisfaction-i.e., the satisfaction that comes from helping others (Stamm 2002)-and is associated with a more prosocial identity, e.g., seeing oneself as a caring person (Grant et al. 2008). In addition, a series of studies by Melwani et al. (2012) demonstrated that people who act compassionately are perceived more strongly as leaders and that perceived intelligence (i.e., how clever and knowledgeable the person is) mediated the relationship between compassion and leadership.

Compassion also affects the relationship between the focal actor and the sufferer. Interview studies suggest that compassion psychologically connects people, resulting in a stronger felt connection between coworkers (Frost et al. 2000, Powley 2009). This connection may arise because compassion breeds trust, as theory suggests (Clark 1987, Dutton et al. 2007). At the same time, if one person is consistently compassionate toward another over time without experiencing compassion flowing in the 
return direction, this lack of reciprocation may solidify status differences or inequalities in the relationship (Clark 1987).

Compassion at work also affects witnesses and bystanders. For example, witnessing compassionate encounters may increase feelings of pride about the way that people in an organization are behaving (Dutton et al. 2007) and may foster elevation, encouraging people to act more for the common good (Haidt 2002). Research suggests that those who have witnessed compassion tend to take less punitive action against others unrelated to the compassion episode who have transgressed in some way (Condon \& DeSteno 2011).

Finally, many have suggested that compassion at work yields collective benefits as well, including higher levels of shared positive emotion (e.g., pride and gratefulness; Dutton et al. 2006) as well as greater collective commitment and lower turnover rates (Grant et al. 2008, Lilius et al. 2008). Case studies of compassion suggest that this process can also build a collective unit-level strength of compassion (e.g., Lilius et al. 2011), a collective capacity for healing (Powley 2009), and overall levels of collaboration (Dutton et al. 2007). Clearly, more extensive empirical investigations of the effects of compassion as a collective capability of organizations are needed.

\section{A Model of the Interpersonal Process of Compassion}

Episodes of people suffering and others responding are ubiquitous in work organizations. Despite their pervasiveness, these interpersonal dynamics have generally escaped systematic study. Our model synthesizes the diverse pieces of research and theory that address this process, revealing what we know and where future research is needed. In performing this synthesis, we highlight that compassion is a fluid, dynamic process in which both the sufferer and the focal actor make sense of the situation and influence each other in ways that can hinder or facilitate compassion.

The interpersonal process of compassion begins with a pain trigger, which initiates suffering in one person who may or may not explicitly communicate distress. The focal actor begins responding to this suffering through three interrelated sub processes-noticing the suffering, feeling empathic concern, and acting to alleviate the suffering (Kanov et al. 2004). Although some researchers have noted that these sub processes sometimes happen simultaneously and that the distinctions between them are blurry (Way 8c Tracy 2012, Miller 2007), we treat the sub processes as distinct for our analytic purposes (Figure 1). Throughout the process, both sufferers and focal actors engage in sense making in that they interpret each other's and their own situations and conditions at various points in time (Atkins \& Parker 2012). These dynamic appraisals can influence what each person notices, feels, and does, thus changing the way an episode unfolds. This process results in outcomes for the focal actor, the sufferer, and the third parties, as discussed in the section above. The final model elements include the contextual features that shape a compassion episode. Most proximate to the sufferer and the focal actor are individual differences and role characteristics that affect what a person is likely to notice, feel, and do as well as how he or she makes sense of the situation. In terms of more distal contextual conditions, research addresses how aspects of the relational context (similarity, closeness, and social power) and organizational context (shared values, shared beliefs, norms, practices and routines, structure and quality of relationships, and leaders' behaviors) relate to the compassion process. Although the broader national-cultural context in which the organization is embedded is likely to influence the unfolding of compassion in the workplace, no research has been done to date, so this is discussed in Future Research Opportunities, below. We unpack Figure 1 in the remainder of this section. 


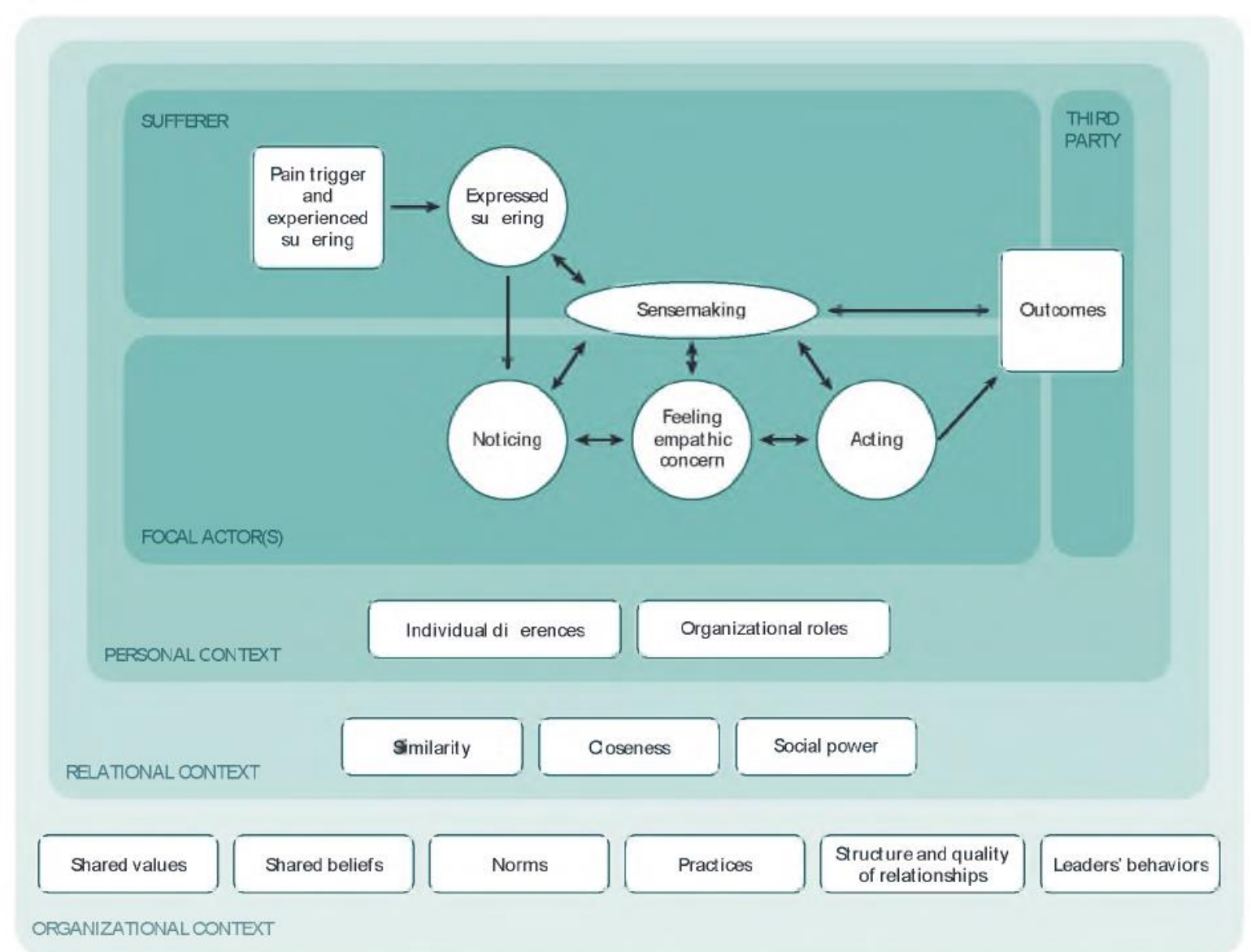

\section{Figure 1}

Subprocesses of response to suffering. The bidirectional arrows between the subprocesses indicate that the processes do not necessarily unfold in a sequential order, and the overall response process can dynamically flow back and forth between subprocesses (Atkins $\&$ Parker 2012).

\section{A Sufferer's Experienced and Expressed Suffering}

The stage for compassion is set when a pain trigger occurs and causes someone to suffer (Dutton et al. 2006). Suffering itself is dynamic, and its intensity and form often change over time (Cutcliffe 2002). Unsure of how to act, sufferers often look to others for cues about what is appropriate or acceptable with regard to whether, when, and how to express their suffering within a workplace (Bento 1994). For example, people dealing with loss may sense that their grief is difficult for others to witness, so they attend to the others' behavior to gauge the willingness to engage with their grief (Goodrum 2008). Although sufferers may feel a need to receive emotional support from others, they may be worried about upsetting people (Goodrum 2008) or may perceive conflicting cues about how to express suffering (e.g., whether it is right or wrong to cry) (Bento 1994). Accordingly, sufferers may underplay their suffering, compartmentalize their distress, or pretend to feel okay (Goodrum 2008). Thus, people not only experience suffering in individualized ways but also manage and express suffering to varying degrees and in different ways. 


\section{A Focal Actor Noticing Suffering}

Noticing suffering is critical; without it, the compassion process ends. Noticing takes place when the focal actor becomes aware of another person's pain (Kanov et al. 2004). Becoming aware of someone's suffering implies that the focal actor is singling out certain cues for conscious processing from his/her ongoing experience at work. Sometimes the awareness and recognition of another's suffering is obvious due to clarity and multiplicity of pain cues. However, particularly in work contexts, these cues are more often faint and ambiguous, making the noticing of suffering an effortful and recurrent process (Frost 2003). Way's (2010) study of compassion in the context of hospice workers suggests that recognizing another's suffering sometimes involves intuition, active listening, and seeking out information to understand the other's situation or condition. Noticing often requires attending to the sufferer as well as to the situation and circumstances surrounding the sufferer (Miller 2007).

\section{A Focal Actor Feeling Empathic Concern}

Compassion depends not only on the noticing of suffering but also on the extent to which a focal actor feels empathic concern (Kanov et al. 2004), defined by Batson (1994, p. 606) as "other- oriented feelings that are most often congruent with the perceived welfare of the other person." This emotional sub process is the dominant way that psychologists have studied and defined compassion (Goetz et al. 2010). Empathic concern involves feelings of sympathy that tend be other-oriented and altruistically-as opposed to egoistically-motivated (Batson 1987). These feelings are a "potent source of motivation to help relieve the empathy-inducing need" (Batson et al. 2007, p. 65).

\section{A Focal Actor Acting Compassionately}

Acting is the sub process that captures the behaviors of the focal actor that are intended to reduce or remedy the sufferer's pain. Atkins \& Parker (2012) term these behaviors compassionate actions, instead of compassionate responding, as a reminder that noticing, empathic concern, and sense making are all part of responding. Acting compassionately can involve a breadth of different behaviors, ranging from mere presence or listening to more elaborated, coordinated, and durable actions that involve directing multiple resources toward a sufferer. These resources can be concrete (e.g., clothing, food, cards) or abstract (e.g., attention, time, concern, creation of safe psychological space) (Frost et al. 2006). Acting compassionately in a work context can often be multilayered and ongoing (Way \& Tracy 2012). It can also be planned or improvised in the moment (Dutton et al. 2006). Acting compassionately includes all of the focal actor's behaviors that are intended improve the experience of the sufferer. Because acting compassionately involves actions intended to reduce the suffering of another person, it differs from social support, whose research focuses on the "availability of helping relationships and the quality of those relationships" (Leavy 1983, p. 5) or on specific behaviors that help another feel more efficacious, accepted, and understood (Horowitz et al. 2001). In some cases, acting compassionately can involve withholding or delaying actions when doing so is believed to be most helpful to the sufferer (Way \& Tracy 2012).

\section{A Focal Actor and Sufferer Engaging in Sense Making}

Throughout the compassion process, both parties engage in sense making. Sense making refers to the interpretive work (Weick 2012) individuals do to turn a disruptive, unintelligible circumstance 
(Weick et al. 2005) "into a situation that is comprehended explicitly in words and that serves as a springboard into action" (Taylor \& Van Every 2000, p. 275). In other words, individuals make sense as they deal with the ambiguity of ongoing, unknowable, unpredictable experiences by developing and updating meanings in an effort to answer the questions, What's the story here? and Now what should I do? (Weick et al. 2005).

A central issue for a focal actor trying to comprehend what is happening during a potential compassion episode is to understand the other's suffering. A focal actor may try to do so by engaging in perspective taking, either by imagining how the sufferer feels or by imagining how he or she would feel in the sufferer's situation (Batson et al. 1997). Although the latter may result in personal distress, both types of perspective taking are positively related to feeling empathic concern for the other (Batson et al. 1997).

Focal actors may also try to understand, explain, and make predictions about the role that a sufferer plays in his/her own misfortunes as well as the role that they play or might play as responders. Atkins \& Parker (2012) draw on cognitive appraisal theory (Lazarus 1991) to identify three appraisals that are important for compassion: the sufferer's deservingness of help, the self-relevance of the sufferer and his/her situation to the focal actor, and the focal actor's self-efficacy. Appraisals about sufferers' deservingness relate to "the moral worth of the other ... [and] the other's complicity in the plight" (Clark 1987, p. 297). Focal actors appraise sufferers as being more deserving if they perceive them as being of good character, trustworthy, cooperative, and altruistic (Atkins \& Parker 2012). Sufferers are deemed less deserving if they are viewed as responsible for their own suffering. For instance, focal actors may think that a sufferer brought about his/her own problems by disregarding common logic (Clark 1987), failing to expend effort to avoid the situation, or violating situational norms or rules (Goetz et al. 2010). Appraisals about self relevance and self-efficacy are more concerned with the focal actor's own situation relative to that of the sufferer. Focal actors may judge the extent to which their own broader values and goals are congruent or incongruent with others' suffering. Additionally, a focal actor makes calculations about his/her own ability to cope with the situation, bring about future outcomes, or prevent undesired outcomes (Atkins \& Parker 2012, Goetz et al. 2010). Although descriptions of these appraisals and their effects show how appraisals can shut down compassion, compassion may also be strengthened for those deemed particularly innocent and deserving, in situations that are particularly self-relevant, and when a focal actor feels particularly capable of acting. Also, whereas Batson et al. (2007) discuss valuing the welfare of the person in need (i.e., perceiving the sufferer as deserving) as an antecedent or precondition for empathic concern, our model suggests a more fluid relationship in which appraisals may occur throughout the process rather than only prior to feeling concern. In this way, it is possible for empathic concern to arise more spontaneously and later be moderated one way or the other on the basis of one or more appraisals.

Sense making is ongoing. Once actors make sense of a situation and often act in response to this "sense," those actions and their consequences generate the raw materials available for the next episode of sense making and lead to new ways of noticing and interpreting (Jeong 8c Brower 2008, Weick 2001). Evidence from research by Crocker 8c Canevello (2008) suggests that sufferers may make sense of what motivates others' supportive or compassionate behavior, and such attributions may influence whether sufferers respond positively to focal actors in future interactions by providing support if the focal actors themselves seem to be suffering. In addition, an ethnography of a volunteer search-and-rescue group by Lois (2001) reveals that the ways in which focal actors help a sufferer make sense of his/her situation 
and his/her role in it enable them to manage their own emotions and enable others to provide the assistance necessary to reduce suffering and resolve the problem at hand. Taken together, these studies show that the dynamic, interpersonal nature of compassion is particularly salient in the sense making sub process as both the sufferer and the focal actor seek to comprehend the situation and their roles in relation to it and each other.

\section{COMPASSION UNFOLDING IN CONTEXT}

As mentioned above, research reveals that attributes and conditions operating at three levels of context (personal, relational, and organizational) affect the process and outcomes of a com-passion episode. Below we review the different features of the levels of context that research has examined to date.

\section{Personal Embedding of the Compassion Process}

The personal context of people involved in a compassion episode encompasses the individual differences and organizational roles of both the focal actor and the sufferer. Because these features are person-specific, we cluster these two contextual features together. However, because studies to date consider only the personal context of the focal actor, we review these elements here and look to future research to consider the personal context of the sufferer.

Focal actors' individual differences. Research suggests that individual differences among focal actors affect compassion sub processes. These individual differences include personality traits and disposition, individual abilities, demographic characteristics, and knowledge. Variation among these attributes helps account for the reasons that focal actors may differ in the way they compassionately respond at work.

Psychologists have examined how individual differences in attachment style are associated with the emotional element of compassion, feelings of empathic concern. Bowlby (1983) first suggested a possible link between the attachment style of an individual, which is formed in early childhood and influenced by the availability and supportiveness of caretakers, and the compassion demonstrated by that individual throughout life. Testing this theory, Mikulincer et al. (2001) primed individuals for a secure attachment style and measured felt empathy (Batson et al. 1989) after reading a story of suffering. Individuals primed for a secure attachment style exhibited more empathy than did a control group. Those with a more secure attachment style have more positive working models of support in times of need, and this support allows them to show support for others (Mikulincer \&c Shaver 2005). In compassion episodes at work, focal actors with more secure attachment styles are more likely to feel greater empathic concern for a sufferer.

A focal actor's personality traits may also influence his/her ability to feel empathic concern when a work colleague is suffering. For example, in one self-report study (Shiota et al. 2006), feelings of compassion were positively correlated with extroversion, agreeableness, and openness to new experiences. Extroversion, an energetic approach toward the social world, is associated with sociability and positive emotions; agreeableness, a prosocial and communal orientation, is associated with altruism and tender-mindedness; and openness is associated with a wide breadth, depth, and complexity in one's mental capacity and life experiences (John et al. 2008). Individuals who are more social, communally 
oriented, and open may more be more likely to attend to others, notice their suffering, and process it in ways that lead to empathic concern.

Psychological flexibility, first defined by Bond et al. (2006), is an ability that affects compassion. It "refers to being open and curious regarding the present moment and, depending on what the situation affords, acting in accordance with one's chosen values" (Atkins \& Parker 2012, p. 528). Atkins 8c Parker (2012) argue that psychological flexibility clears the path for compassion by centering individuals on the present moment in a nonjudgmental way, potentially impacting all aspects of the process. In particular, mindfulness and present-moment contact increase the likelihood of noticing suffering in work contexts by directing the focal actor's attention to the situation and its immediate cues (Atkins 8c Parker 2012). The reduced personal distress associated with psychological flexibility, stemming from the use of fewer attentional resources to control the situation, leads to more empathic concern for others because (a) stepping back from one's own emotions leaves room for contextualizing others' emotions, (b) lessened automatic reactivity assists in allowing sense making to unfold, and (c) reduced defensiveness and enhanced self regulation facilitate taking action (Atkins 8c Parker 2012).

Research suggests that two demographic characteristics of the focal actor impact an interpersonal compassion episode: gender and socioeconomic status (SES). Historically, data regarding gender differences related to compassion have tended to be mixed (e.g., Broverman et al. 1972, Oveis et al. 2010, Stellar et al. 2012, Taylor et al. 2000). For instance, in one of three studies, Stellar et al. (2012) found that women tend to report elevated levels of empathy. In contrast, Mercadillo et al. (2011) found no differences in reported compassionate feelings (empathy) between men and women after the participants viewed compassion-inducing photos. In this same study, functional magnetic resonance images revealed underlying differences in brain activation: Women have more diverse activation in the frontal lobe, the temporal lobe, and the anterior cingulate cortex; men have activation concentrated in the cerebellum and the anterior cingulate cortex. Taken together, these results suggest gender differences in the experience of compassionate feelings, with women experiencing more elaborate activation in emotional and empathic brain processes than men, but men and women did not differ in baseline amounts of compassion (Mercadillo et al. 2011).

Research also suggests that individuals with lower SES are more likely to perceive a sufferer as more distressed and to feel more empathic concern (Kraus et al. 2012, Stellar et al. 2012). An increase in perceived distress results from two mechanisms (Stellar et al. 2012): being more empathically accurate (Kraus et al. 2010) and reacting more negatively to threats impacting others (Chen 8c Matthews 2001). Empathic accuracy-defined as the accurate identification of the emotions of others (see below)-stems from an increased dependence on external resources, which increases attention to context and the surrounding environment (Kraus et al. 2010). Increases in attention on the part of lower-SES individuals make them more likely to notice suffering communicated through behavioral rather than verbal cues. Heightened reaction to threats is a conditioned response resulting from unpredictable environments and a bias toward appraising the world as threatening (Chen 8c Matthews 2001). Lower-SES individuals are also more likely to exhibit physiological cues related to the emotions of individuals with whom they are interrelating, such as mirroring the cardiovascular reactivity of a suffering other (E. Page-Gould, K. Koslov \& W.B. Mendes, unpublished manuscript), demonstrating a higher likelihood of empathic concern. Stellar et al. (2012) also found greater levels of empathic concern among lower-SES individuals after the participants watched compassion-inducing films. Taylor et al. (2000) suggest that individuals develop alternative strategies to cope with stressful environments and external threats, like those faced 
by lower-SES individuals, by engaging in more affiliated behaviors and building cooperative networks for withstanding challenges, both of which are conducive to compassion (Stellar et al. 2012).

Individuals also vary in their familiarity with and knowledge about certain kinds of suffering. A focal actor's levels of knowledge and experience with the sufferer's situation are also likely to affect whether he/she notices the signs that someone is suffering, is able to take the sufferer's perspective (and impute meaning that prompts action), and acts compassionately. For example, in a detailed account of how one Big Ten university business school (BTUBS) responded to students' suffering from damage and loss from a house fire, the person who played the pivotal role in galvanizing the noticing of suffering and mobilizing of resources for the students was a person who had survived a house fire herself and thus had relevant experience (Dutton et al. 2006). This person had seen firsthand what kinds of compassionate actions were most helpful in the case of a house fire, and she applied this knowledge in the role she improvised in the compassion episode.

A focal actor's organizational role. Roles capture the behavior that is expected of a particular person in an organization (Katz \& Kahn 1978). Any individual can have singular or multiple roles at any one point in time, and these roles can vary in how ambiguous or clear-cut they are (Kahn et al. 1964). Roles that people take or are given in work organizations endow them with resources (such as status and legitimacy; Baker \& Faulkner 1991) that facilitate compassion. At the same time, roles are defined by the expectations from the organization and from others interacting with a role incumbent that, depending on the features of the role, may constrain compassion.

Researchers suggest that three features of the focal actor's role are important in shaping the compassion process. First, the level of professionalism applied to certain roles may create expectations that one should not overly express emotion or act in too caring a fashion toward someone who is suffering. When individuals are socialized into a role, they learn the degree and kind of emotional labor that is expected (Miller 2002, p. 588). If people have been socialized into roles in which emotion or caring is considered to be unprofessional, not legitimate, or not self relevant (Atkins \& Parker 2012), then several sub processes of compassion are likely to be weak or nonexistent. For example, Frost et al.'s (2000) analysis of compassion narratives in university settings and Miller's (2002) account of her own response to the bonfire disaster at Texas A8cM made clear that being in the role of professor created doubts about how to be professional and caring at the same time in the face of students' and colleagues' suffering. Her experience suggested that with her professional role, she found it more difficult to justify being compassionate toward students. Second, roles also vary in the level of cognitive load that they impose on role holders; therefore, because of ideas about limits or constraints on cognitive or attentional resources (Miller 1956), people in some roles are likely to have more limited resources to devote to the compassion sub processes. Indirect evidence for this claim comes from experimental studies of how attentional demands affect people's ability to sympathize with children in pain. The study by Dickert \& Slovic (2009) demonstrates that when people confront others, in this case, images of single victims, they respond emotionally with more sympathy than they do if they are distracted by other victims. The researchers use this study to argue that attentional demands affect emotional responses. In the case of a focal actor, this could mean that when people experience role overload or demanding tasks, their ability to feel empathic concern for a sufferer may be constrained.

The idea that the emotional load carried by a role holder affects a person's capacity to compassionately respond is recognized by people who study roles that involve extensive emotional work. In 
contrast to emotional labor, the idea of emotional work or emotional care emphasizes that some jobs require authentic emotional responsiveness and investment in others (e.g., Lilius 2012, Lopez 2006). Sometimes this type of emotional work can deplete resources and make it difficult to respond to people in pain.

Third, individuals can chose to take on higher emotional loads through the types of roles they design for themselves. For example, research on the role of toxin handlers in work organizations suggests that some employees voluntarily take on the role of attending to and facilitating the processing of human pain at work (Frost 8c Robinson 1999). People who take on this role often purposively notice pain and engage in compassionate actions when pain is detected (e.g., through listening, holding space, and extricating people from painful situations) (Frost 2003). In terms of understanding compassion at work, the idea of toxin handlers suggests that employees may exercise choice in the degree to which they take on and respond to the suffering of others.

\section{Relational Embedding of the Compassion Process}

Compassion episodes unfold in the context of the relationship between the sufferer and the focal actor. Research suggests that three features of the relational context shape compassion: similarity, closeness, and social power.

\section{Similarity.}

Similarity refers to the extent to which focal actors perceive that sufferers are like them in a particular dimension or in general. Valdesolo \& DeSteno (2011), for example, conducted an experiment to examine the role of synchrony and similarity in altruistic responses toward victims of moral transgressions. The authors found that participants perceived themselves as similar to the victim and liked the victim more when parties (i.e., participant and confederate victim) were engaged in synchronous action (i.e., tapping a rhythm in sync). In turn, perceived similarity, but not liking, was positively associated with self-reports of compassionate feelings for the victim, and compassionate feelings mediated the positive effect of perceived similarity on the amount of time that participants spent helping the victim with an unjustly time-consuming task. Valdesolo \& DeSteno (2011) argue that similarity mediates the effect of synchrony on compassionate feeling and action because it creates a sense of unity, directs attention to similar others' situations, generates interest in their well-being, and motivates helping behavior. Interestingly, the relationship between similarity and compassion seems to be bidirectional. Across three studies in which compassion was either induced or measured as a trait, Oveis et al. (2010) found that it was positively associated with increased perceived self-other similarity, particularly to weak or vulnerable others. In this way, compassion brings about the very condition that creates more compassion.

\section{Closeness.}

Relationships at work also vary in how close or distant people are from one another.

Relationship closeness captures how familiar, intimate, and proximate one person is to another. Several researchers have implied that relationship closeness should impact a compassionate episode in a variety of ways. For example, Clark (1987) suggests that relationship closeness affects the felt obligation to respond to another person's pain, because when people are close, they have wider sympathy margins. In other words, if the connection that two people share is deeper, then the range of events for which 
sympathy (or in this case, compassion) is appropriate is broader, and the sympathy felt for the relationship partner is more extensive and more genuine. The result is that focal actors feel they should inquire more into how a person is doing, have deeper knowledge of past incidents of pain, and thus be more able to compassionately respond to a sufferer (Clark1987). Similarly, Frost et al. (2000) found that knowing someone well helped employees know when and how to act toward someone's suffering. Way \& Tracy (2012) found that stronger identification created closeness, which made it easier for a focal actor to relate to and respond to the sufferer. Relationship closeness provides the knowledge and emotional bonding that facilitate the recognition that someone is suffering, as well as when and how to respond in meaningful ways.

\section{Social power.}

Citing Fiske (1993), van Kleef et al. (2008) state that social power "reflects the relative influence an individual exerts over other people's outcomes, and is experienced in terms of the sense of control, agency, and freedom" (pp. 1315-16). It is a characteristic of dyadic relationships at work that can affect both the sufferer's expression of suffering and the likelihood that focal actors will engage in compassion. For example, those in positions of leadership are generally expected to "keep a stiff upper lip" and continue with their work as normal, despite whatever distress or hardship they may be experiencing at work (Bento 1994). A person with higher status, such as a leader, who has greater social power relative to others is less likely to express suffering. This effect of social power likely makes it more difficult for others to notice a leader's suffering and respond with compassion.

Social power also affects compassion episodes through its effects on social perception. Consistent with the approach/inhibition theory of power (Keltner et al. 2003), research shows that higher-power individuals tend to experience and express more positive emotion and less negative emotion than do lower-power people (Berdahl \& Martorana 2006, Galinsky et al. 2006). Experiments by Galinsky and colleagues (2006) show that individuals with more power are less inclined to adopt others' perspectives, and they are less accurate at perceiving others' emotions. These dynamics may partly explain differences in the distress and felt compassion for others. In a study in which pairs of individuals shared personal stories of events that caused suffering, van Kleef et al. (2008) found that higher levels of sharers' distress caused increases in compassion and distress only for listeners with lower, as opposed to higher, power. This relationship may be even stronger in organizations because employees pay particular attention to supervisors' behavior and are concerned with the quality of relationships they share (Tyler \& Lind 1992).

The effects of social power are not, however, always negative. In some circumstances, social power can enhance or facilitate empathic accuracy (Ickes et al. 1990, Levenson \& Ruef 1992). Given that power increases the tendency to behave in a goal-congruent fashion, Cote and col-leagues (2011) hypothesized that moderating the effects of power may explain conflicting findings with regard to whether prosocial orientation-a focus on the needs of others and an inclination to enhance the welfare of others (Batson \& Shaw 1991, Grant 8c Mayer 2009)-influences empathic accuracy. In a series of three experiments, Cote et al. (2011) found that people with trait or induced prosocial orientation had better empathic accuracy only when they were dispositionally higher in power or induced to feel more power. Thus, although social power may hinder compassion in some situations, it may also facilitate noticing and feeling when those who are higher in power are already oriented toward compassion. 


\section{Organizational Embedding of the Compassion Process}

Compassion unfolds within the boundaries of an organization. Research suggests that six features of the organization relate to the process and outcomes of compassion: shared values, shared beliefs, norms, practices, structure and quality of relationships, and leaders' behaviors.

\section{Shared values.}

Shared organizational values refer to what people in an organization believe is important. Organizational values sensitize individuals so they are able to notice certain situations and actions (Dutton et al. 2006) and shape sense making (e.g., Smircich 1983); such values also provide an impetus for certain kinds of actions (O'Reilly \& Chatman 1996). Organi2ational values communicate what is significant, and, as a result, they affect the compassion process. For example, Dutton et al.'s (2006) study of one BTUBS's response to students who suffered loss from a house fire suggests that the value of treating individuals as whole people affected the noticing of suffering. This organizational value helped foster the sharing of the news about the students' suffering while also legitimizing their painful circumstances as real and significant. This finding is consistent with Bento's (1994) argument that in organizations in which people can bring only their professional selves to work (so the whole person is less valued), grief will be stifled and thus the compassion process will be restricted or nonexistent.

Research also suggests that the shared value of care is important in explaining a higher level of compassionate action. In a recent study of retrospective accounts of how work organizations responded to the floods of 2011 in Brisbane, Australia, Simpson et al. (2013) found that the value of caring (or what the authors termed a caring philosophy) distinguished employers who acted in more or less compassionate ways.

\section{Shared beliefs.}

Whereas values pertain to what is viewed as important, shared organizational beliefs capture what organizational members believe to be true (Trice \& Beyer 1993). In the study of the student fire at the BTUBS cited above (Dutton et al. 2006), the shared belief that it was okay to "put one's humanity on display" made sharing the circumstances of the three students more likely, facilitating the speed and scope of compassionate responding.

In addition, shared beliefs that pertain to the permeability of boundaries between people's personal and professional lives also apply to the understanding of patterns of compassion (Lilius et al. 2011). In organizations whose members believe that it is acceptable and desirable to know about a fellow member's personal life and act on that knowledge (e.g., Ashforth et al. 2000), individuals are more likely to share that they are in pain at work, and colleagues may feel more justified to notice, feel, and act to alleviate the pain.

\section{Norms.}

Normative patterns of behavior that typify an organization can shape both the expression of suffering and how a focal actor is likely to respond during episodes of compassion. Norms capture the pattern of an organization's expected behaviors that are shaped over time and that constrain future action to comply with the norms (Schein 1985). For example, there are often norms about displays of 
grief at work that affect compassion. In one study of employees' grief responses to losing family members to murder, researchers found that "grief displayed at the wrong time, in the wrong place, or to the wrong person presented a norm violation and often brought negative reactions from others" (Goodrum 2008, p. 429). This observation fits findings that organizational norms tend to "reward the repression of negative emotion ... Sadness and grief should be checked at the door as they are too heavy for the rarified emotional atmospheres of the workplace" (Bento 1994, p. 35).

Organizational norms about emotional expression are sometimes termed feeling rules, which shape whether and how emotions get displayed at work (Hochschild 1983). These rules can limit how suffering gets expressed and thus impact the noticing and sense making around an employee's suffering as well as compassionate actions. Some researchers have used the term expression tolerance to describe these norms around emotional expression, noting that anger expressions at work (as a form of personal pain expression) are likely to be followed by com-passion when expression tolerance is high (Zenteno-Hidalgo \& Geddes 2012). Organizational norms also affect compassionate actions. For example, some researchers argue that norms of self-interest shape whether people feel that it is socially inappropriate to act compassionately. In an experimental study, Molinsky et al. (2012) demonstrated that priming an economic schema (a knowledge structure that prioritizes rationality, self-interest, and efficiency) reduced how compassionately a person communicated bad news to another person (in this case, loss of a scholarship). Their research also suggests that this impact happened by reducing empathy and increasing felt unprofessionalism. Thus, norms - in this case, shared beliefs that favor self-interest, efficiency, and/or rationality-may dampen compassion toward another through multiple pathways.

\section{Organizational practices.}

Organizations develop repeated patterning of actions that researchers term practices (Orlikowski 1992), which also shape the compassion process. Sometimes these practices get formalized as programs due to the need for efficiency and coordination. Several studies detail how organizational practices provide repeated ways of doing that shape what unfolds during compassion episodes at work. These practices encourage people to pay attention to particular kinds of feelings, provide frames for making sense of the sufferer's and focal actors' situations, and provide scripts for certain kinds of actions. Three detailed case studies (Dutton et al. 2006, Lilius et al. 2011, McClelland 2012), including one survey study in a health-care setting (McClelland 2012), document the importance of organizational practices in shaping compassion. All these studies suggest that organizational practices directly affect the likelihood and form of compassion in a particular case of suffering, as well as the overall pattern of compassion across a range of episodes.

Research supports the importance of four sets of practices that impact compassion episodes. First, practices that select people for employment on the basis of their relational skills are likely to create an organization where more people are likely to notice, feel, and act with compassion at work. For example, McClelland's (2012) research showed that hospitals used both behavioral interviewing and potential employees' responses to claims about being a culture of compassion in order to select people who were more likely to behave compassionately at work. Second, employee assistance and employee support practices that give people at work the opportunity and means for helping employees in need also facilitate compassion. For example, Grant et al. (2008) found that participation in a practice that allowed the donation of a dollar a week to an organizational fund helping employees in need strengthened the degree to which employees acquired a prosocial identity as caring people. Building on 
the idea that one's identity shapes what one notices and how one responds to a situation, we would expect a caring identity to foster caring behaviors directed toward people who are suffering at work. McClelland (2012) found that the existence of formal employee support practices (including practices that provided both emotional support and material support) were important in fostering compassion toward the hospital's patients. A third employee support practice that impacts compassion episodes is notification of harm: procedures for notifying other people if someone at work is experiencing painful circumstances. For example, John Chambers, CEO of Cisco, established HR communication practices to let him know of anyone in the global company who had experienced a severe loss, such as a serious illness or the death of a family member, so that he could personally contact them (Dutton et al. 2002). This practice not only facilitates the noticing of suffering but also communicates a value that responding to suffering is important.

Fourth, organizations have practices that reward and recognize people for their helping (McClelland 2012). Where people are routinely rewarded and recognized for helping one another, there is a premium put on noticing need and responding. In addition, these types of practices encourage the interpretation that suffering is legitimate and real and are likely to foster positive meaning associated with being a contributor or giver to others, thus further fostering prosocial and helpful actions.

\section{Structure and quality of relationships.}

Compassion is also shaped by the overall structure and quality of relationships between people in the organization. A dyadic episode of compassion is triggered and unfolds in the context of a relational fabric of the organization. The relational fabric of an organization is captured by both the patterning of network ties and the quality of the connections between people in those ties. When network ties are strong, news about someone's painful circumstances is more likely to spread. This network-tie effect became evident when notification of harm for the three students impacted by the fire at the BTUBS traveled quickly across multiple subnetworks in the school through rapid interpersonal and electronic communication (Dutton et al. 2006). Network ties facilitate social interactions, which are the basis for spreading feelings and coordinating compassionate actions (Madden et al. 2012). When the ties between organizational members are also high quality (e.g., characterized by mutuality, positive regard, and vitality) (Dutton \& Heaphy 2003), people are likely more emotionally attached to one another (Kahn 1998), and this attachment facilitates noticing, feeling, and acting toward someone if he or she is suffering (Lilius 2012). The link between connection quality and compassion was highly evident in the case study of the Midwest Billing Department (Lilius et al. 2011), where people characterized their relations as loving and caring. As Fredrickson (2013) suggests, this form of connection is marked by positivity resonance (i.e., the joint effects of three neurobiological events: the sharing of positive emotions, a synchronizing of both persons' biochemistries, and a motivation to invest in each other's well-being), which fosters resilience and other adaptive responses. In the case of organizations, these higher-quality connections make it easier for people to express suffering as well as for others to respond to suffering, fostering the allocation of resources to people in pain (Lilius et al. 2011).

\section{Leaders' behaviors.}

The last cluster of organizational features that affects compassion at work involves leaders' behaviors. Leaders play a symbolic and instrumental role in signaling and modeling the necessary and appropriate responses to suffering. Examples of leader compassion described in popular texts on leadership (e.g., Boyatzis \& McKee 2005) and exhibited in times of crisis, as in the wake of 9/11 (e.g., 
Dutton et al. 2002), illustrate how leaders' actions help people frame the meaning of suffering as well as model and anchor appropriate acts of compassion. In addition, leaders' formal power and status give them the means to shape the other contextual factors mentioned above (e.g., shared values, shared beliefs, practices, structure and quality of relationships) that facilitate or retard compassion. The aforementioned example in which Cisco CEO John Chambers created notification-of-harm practices that facilitate quick identification of employees who are experiencing a severe loss (Dutton et al. 2002) is a good illustration of how leaders shape contexts in which compassion takes place. Although books suggest that leadership is central to work-based compassion (e.g., Frost 2003), to date no systematic empirical studies address how leadership matters in terms of compassion at work.

In sum, features of the organizational context are critical for understanding how compassion episodes unfold. These contextual factors touch the full range of sub processes that compose a compassion episode, meaning that there are multiple pathways by which their impact on this vital interpersonal process is felt.

\section{KEY OBSERVATIONS ABOUT RESEARCH TO DATE ON COMPASSION AT WORK}

Ample evidence supports the idea that compassion at work matters, and our review brings order to some of the complexity in compassion processes at work. Three observations stand out. First, compassion has multiple sub processes that may occur in different orders, can be recursive and repeated, and may be affected by different antecedents. Each sub process - noticing suffering, feeling empathic concern, acting to alleviate suffering, and engaging in sense making about what has occurred-is important, and each needs to be understood to fully comprehend the what, the how, and the when of compassion at work. In addition, we need to know more about the relationships between these sub processes. Second, compassion at work has been described and researched primarily from the perspective of the focal actor. Although compassion at work has been theorized as a dyadic process, it has been empirically studied more as an individual-level process, with a focus on the focal actor; we know less about how the sufferer shapes the process and its outcomes. Third, research suggests that three levels of nested context (personal, relational, and organizational) shape the compassion process by affecting one or more sub processes that impact the focal actor's responses primarily.

Table 1 summarizes the major links between the different aspects of context and the compassion process. As the summary suggests, each study tends to look at a single part of the compassion process, leaving considerable room for future researchers to take a more holistic and systematic approach to determining how the patterning of contextual enablers or disablers shapes whether and how interpersonal compassion unfolds. Also unclear is how the organization shapes empathic concern. Just as inquiry into dyadic relationships at work is fragmented (Ferris et al. 2009), the fragmented inquiry of compassion research has limited our capacity to draw clear conclusions about how the compassion process works.

\section{Future Research Opportunities}

Compassion at work is a research topic that is still in its infancy. In general, research on compassion is dominated by theoretical and theory-building studies, opening wide possibilities for theorytesting studies that address both the process and the outcomes of compassion at work. We see five areas in which future research would be particularly valuable: exploring and testing how compassion matters at work, exploring and testing the sufferer's role in and experience of the compassion process, 
highlighting the interactional and relational nature of compassion, examining cross-cultural differences in compassionate responding at work, and improving the measurement and testing of compassion.

Explore and test how compassion matters at work. This review has itemized what research has documented about the impacts of interpersonal compassion at multiple levels of analysis. However, more systematic research that considers the short-term and long-term impacts of compassion on job attitudes (e.g., engagement, thriving), job behaviors (e.g., prosocial behaviors, creativity, ethical actions), job performance, health outcomes for individuals (episode participants and third parties, including employees, customers, buyers, and other organizationally relevant parties), and patterns of future interactions by organizational members (Lawrence \& Maitlis 2012) is clearly warranted. Additionally, it would be fruitful to examine the way in which a single compassion episode unfolds and affects the potential for compassion in subsequent encounters with suffering. We know from some empirical work that when sufferers experience compassion at work, it alters their conceptions of their coworkers, themselves, and their organizations through sense making (Lilius et al. 2008). Future research might examine how people learn from compassion episodes and how these lessons are applied to future situations that involve suffering and the potential for compassion. Whereas the research on practices and compassion explains one way that compassion gets institutionalized and infused into the organization's culture (Lilius et al. 2011, McClelland 2012), much more research on institutionalizing mechanisms would help explain patterns of compassion at work over time. In sum, we believe that much more could be done to systematically test the effects of interpersonal compassion at work on a broader set of dependent variables as well as test the mechanisms through which they operate.

Explore and test the sufferer's role in and experience of the compassion process. We need to know much more about the sufferer in the compassion process. For example, how does the personal context of the sufferers (in particular, their individual differences and their role characteristics) matter for compassion? How do sufferers communicate how they are in pain, and what difference do information and feelings conveyed about suffering and desired responses make for how another individual (or group of individuals) notices, feels, and acts toward this person? The literature tends to take for granted that sufferers will be open to, ready for, or accepting of compassionate responses, but this may not be the case. Research on social support at work, for example, reveals that actions intended by others as helpful may be unwanted, and when that is the case, these actions may actually be harmful (Beehr et al. 2010). Even if sufferers want a compassionate response, they may have ideas that differ from the focal actor's ideas about what would be most helpful. Although research has certainly shown that employees experience personal and organizationally induced suffering, it has not yet considered how employees in pain shape how others respond constructively in the form of compassion.

Similarly, we need to know how sufferers shape and respond to the compassionate acts of others. How do they feel about, make sense of, and respond to these acts of care? How do they evaluate the focal actors' intentions and the compassionate actions themselves? Furthermore, it is important to recognize that individuals are usually in numerous dyadic relationships with others at work (e.g., superiors, coworkers, subordinates, clients), and together these relationships form the larger web of relationships within which single dyadic interactions occur (Ferrin et al. 2006). When a particular individual is suffering, more than one individual or group may be responding to the sufferer independently of one another. We need to know how individuals experience the unfolding of multiple compassion episodes 
Table 1 Summary of relationships between different aspects of context and subprocesses in compassion at work

\begin{tabular}{|c|c|c|c|}
\hline Subprocess & Personal context & Relational context & Organizational context \\
\hline $\begin{array}{l}\text { A sufferer's } \\
\text { experienced } \\
\text { and expressed } \\
\text { suffering }\end{array}$ & $\begin{array}{l}\text { Professionalism may decrease } \\
\text { expressions of suffering (Atkins \& } \\
\text { Parker 2012) }\end{array}$ & $\begin{array}{l}\text { Increased status may lead a sufferer } \\
\text { to be less likely to express } \\
\text { suffering (Bento 1994, Berdahl \& } \\
\text { Martorana 2006) }\end{array}$ & $\begin{array}{l}\text { Organizationally shared beliefs } \\
\text { shape what emotions are } \\
\text { acceptable to put on display and } \\
\text { when (Ashforth et al. 2000, } \\
\text { Goodrum 2008), sometimes } \\
\text { rewarding the suppression of } \\
\text { negative emotion (Bento 1994) } \\
\text { Shared beliefs about permeable } \\
\text { boundaries between personal } \\
\text { and public life allow individuals to } \\
\text { express suffering at work (Dutton } \\
\text { et al. 2006, Lilius et al. 2011) } \\
\text { Feeling rules, including } \\
\text { expression tolerance, impact } \\
\text { how and when individuals } \\
\text { express suffering at work } \\
\text { (Hochschild 1983, Miller 2002) }\end{array}$ \\
\hline $\begin{array}{l}\text { A focal actor } \\
\text { noticing } \\
\text { suffering }\end{array}$ & $\begin{array}{l}\text { Psychological flexibility increases } \\
\text { the noticing of suffering (Atkins \& } \\
\text { Parker 2012) } \\
\text { Lower SES increases the noticing } \\
\text { of suffering (Kraus et al. 2010) } \\
\text { The more experience with a type of } \\
\text { suffering, the greater the } \\
\text { likelihood of noticing the } \\
\text { suffering (Dutton et al. 2006) }\end{array}$ & $\begin{array}{l}\text { A closer relationship with the } \\
\text { sufferer causes the focal actor to } \\
\text { be more likely to inquire about } \\
\text { suffering (Clark 1987, Frost et al. } \\
\text { 2000, Way \& Tracy 2012) }\end{array}$ & $\begin{array}{l}\text { The shared value of treating } \\
\text { individuals as whole people } \\
\text { facilitates communication about } \\
\text { suffering (Dutton et al. 2006) } \\
\text { High-quality relationships in an } \\
\text { organization increase the } \\
\text { likelihood of noticing (Dutton } \\
\text { et al. 2006) }\end{array}$ \\
\hline $\begin{array}{l}\text { A focal actor } \\
\text { feeling } \\
\text { empathic } \\
\text { concern }\end{array}$ & $\begin{array}{l}\text { A more secure attachment style } \\
\text { increases feelings of empathy } \\
\text { (Mikulincer \& Shaver 2005) } \\
\text { Personality traits of extroversion, } \\
\text { agreeableness, and openness } \\
\text { increase feelings of empathy } \\
\text { (Shiota et al. 2006) } \\
\text { Psychological flexibility increases felt } \\
\text { empathy (Atkins \& Parker 2012) } \\
\text { Individuals with a lower SES are } \\
\text { more empathically accurate (Kraus } \\
\text { et al. 2010) } \\
\text { Constraints on cognitive or } \\
\text { attentional resources may reduce } \\
\text { empathic feelings (Dickert \& Slovic } \\
\text { 2009) } \\
\text { People in roles that focus on } \\
\text { emotional work requiring authentic } \\
\text { feeling may experience more } \\
\text { empathic concern (Lopez 2006) }\end{array}$ & $\begin{array}{l}\text { Self-other similarity increases } \\
\text { feelings of compassion (Valdesolo } \\
\text { \& DeSteno 2011) } \\
\text { High status may make individuals } \\
\text { less likely to be empathically } \\
\text { accurate (Galinsky et al. 2006) } \\
\text { Social power moderates the effect } \\
\text { of sufferer distress on responder } \\
\text { compassion such that the } \\
\text { relationship is significant only for } \\
\text { those with less power (van Kleef } \\
\text { et al. 2008) } \\
\text { Social power strengthens the } \\
\text { positive relationship between } \\
\text { prosocial orientation and } \\
\text { empathic accuracy (Côté et al. } \\
\text { 2011) }\end{array}$ & \\
\hline
\end{tabular}


Table 1 (Continued)

\begin{tabular}{|c|c|c|c|}
\hline Subprocess & Personal context & Relational context & Organizational context \\
\hline $\begin{array}{l}\text { A focal actor } \\
\text { acting to } \\
\text { alleviate } \\
\text { suffering }\end{array}$ & $\begin{array}{l}\text { Psychological flexibility increases } \\
\text { actions taken (Atkins \& Parker } \\
\text { 2012) } \\
\text { People who take on roles like those } \\
\text { of toxin handlers may exhibit } \\
\text { more compassionate actions } \\
\text { (Frost 2003) }\end{array}$ & $\begin{array}{l}\text { A closer relationship with the } \\
\text { sufferer causes the focal actor to } \\
\text { be more likely to act (Clark 1987, } \\
\text { Frost et al. 2000, Way \& Tracy } \\
\text { 2012) }\end{array}$ & $\begin{array}{l}\text { People in organizations with the } \\
\text { shared belief that it is acceptable } \\
\text { to know about and act on an } \\
\text { individual's personal life are } \\
\text { more likely to act to alleviate } \\
\text { suffering (Ashforth et al. 2000) } \\
\text { In organizations with shared } \\
\text { values that emphasize care, } \\
\text { people are more likely to act } \\
\text { compassionately (Simpson et al. } \\
\text { 2013) } \\
\text { Norms of self-interest make } \\
\text { individuals less likely to act } \\
\text { compassionately (Molinsky } \\
\text { et al. 2012) } \\
\text { Organizations have practices that } \\
\text { make certain compassionate } \\
\text { actions easier to execute than } \\
\text { others (Dutton et al. 2006, Lilius } \\
\text { et al. 2011, McClelland 2012) } \\
\text { Leaders' behavior models } \\
\text { appropriate responses to } \\
\text { suffering (Boyatzis \& McKee } \\
2005 \text {, Dutton et al. 2002) }\end{array}$ \\
\hline $\begin{array}{l}\text { A focal actor } \\
\text { and sufferer } \\
\text { engaging in } \\
\text { sensemaking }\end{array}$ & $\begin{array}{l}\text { Psychological flexibility through } \\
\text { lessened automatic reactivity allows } \\
\text { sensemaking to unfold more fully } \\
\text { (Atkins \& Parker 2012) } \\
\text { A focal actor's knowledge about the } \\
\text { sufferer's situation is likely to affect } \\
\text { whether the focal actor is able to } \\
\text { take the sufferer's perspective } \\
\text { (Dutton et al. 2006) }\end{array}$ & $\begin{array}{l}\text { Individuals with more power are } \\
\text { less inclined to adopt others' } \\
\text { perspectives (Galinsky et al. 2006) }\end{array}$ & $\begin{array}{l}\text { Feeling rules impact sensemaking } \\
\text { around an employee's suffering } \\
\text { (Hochschild 1983) } \\
\text { Leaders' attitudes help frame the } \\
\text { meaning of suffering associated } \\
\text { with large events such as } 9 / 11 \\
\text { (Dutton et al. 2002) }\end{array}$ \\
\hline
\end{tabular}

"SES, socioeconomic status.

simultaneously and how sufferers make sense of compassion from one person in light of the responses they do or do not invoke in others. At a more basic level, it might be informative to explore whether or when sufferers realize that others are trying to respond to them in a compassionate manner. Compassion may go unnoticed by the sufferer when it is so skillfully accomplished that it is sometimes rendered invisible (Frost 1999).

Highlight the interactional and relational nature of compassion. Questions about the role and experience of the sufferer highlight the interpersonal nature of compassion. In addressing the literature's blind spot with regard to the sufferer's role in and experience of a compassion episode, scholars should be careful not to overcorrect and focus only on the sufferer while excluding the focal actor. We encourage future research that examines how these two parties, and potentially third parties, interact and intentionally or unintentionally alter each other's thoughts, feelings, and behavior throughout a particular compassion episode or over a series of episodes. Researchers might consider how focal actors determine whether sufferers are resistant to compassionate responses, and if so, when and how they might attempt to overcome such resistance. Further work to clarify how the power of the 
focal actor affects the range and nature of compassionate actions would be a useful contribution. Future compassion research might also focus on how the nature and quality of the relationship between a sufferer and a focal actor change during a compassion episode and how changes in connections last and affect other types of interactions.

Whereas our review has highlighted how attentional, cognitive, and emotional processes matter primarily from the perspective of the focal actor, we need to know much more about the relational mechanisms that undergird the compassion process. In particular, we believe that it would be fruitful to theorize beyond a view of compassion episodes that assumes participants are engaged in a type of social exchange process (Blau 1964), in which focal actors give com-passion to sufferers who receive it and there is a type of over-time motivation to achieve some balance of trade. Even in more sociological accounts of compassion (or sympathy), this focus on exchange occurs, here in terms of emotional currency, when people make gestures "that symbolize the sentiments of one person, which are of use, advantage or value to another" (Clark 1987, p. 297).

Future research might explore alternative models of interrelating at work that are less directly instrumental and more embodied as potentially fruitful candidates for understanding something as basic and human as the dynamics of compassion at work. For example, Fredrickson (2013) offers a theory of positivity resonance to account for how moments of connectivity (such as moments of interpersonal compassion) benefit both people in an interaction through a natural syncing up of people's bodies and brains in ways that foster health and well-being. This model differs from a social exchange view of what motivates human interaction in that it points to how human beings' biological systems are exquisitely designed to detect and respond to one another's changes in moods without cognitive mediation or calculation of what is given or received in interaction. Fredrickson's theory of positivity resonance writes back in some of the biological bases and consequences of short-term interactions (Heaphy \& Dutton 2008) that provide a different account of why compassion matters at work. The general point is that we need richer accounts of the relational mechanisms underlying compassion to better explain when and how this process unfolds at work, and with what consequence.

Examine cross-cultural differences in compassionate responding at work. Surprisingly little theorizing has been offered about national-cultural influence on compassion at work. A few researchers have looked at how societal culture shapes beliefs around suffering and what is de-serving of compassion (Clark 1987, Hazen 2008), including when suffering may be attributable to the sufferer's prior actions (Sullivan et al. 2012) and how culture impacts the meaning and motivations for compassion (Kitayama \& Markus 2000). However, cultural factors become even more critical as we seek to understand how compassion unfolds in an ever-growing global working context.

Societal culture may influence norms, including appropriate feeling rules, how suffering is expressed in the workplace, what responses are deemed effective in alleviating suffering, and what beliefs and values may influence the importance placed on those responses. Many questions need to be explored: Across different cultures, how is suffering expressed in the workplace? Are all cultures equally perceptive in noticing the pain of coworkers? Are different types of suffering considered acceptable to discuss in the workplace across cultures? How do appropriate responses to suffering in the workplace vary? Are impacts of compassion in the workplace the same across cultures?

Improve the measurement and testing of compassion. Testing the impacts of compassion will also require the development and testing of better measures of interpersonal compassion at work. 
Measures will need to treat compassion as a process that is captured from the perspective of both participants in the process. For the focal actor, measures will need to focus on the degree and dynamics of the noticing of suffering, the degree and dynamics of the empathic concern for the other, and the intentions and actions directed toward the sufferer. For the sufferer, measures will need to capture the experience of suffering (and its dynamics over time) as well as the perceived compassion or the degree to which a sufferer believes that another person notices their suffering, feels empathic concern, and acts to alleviate the suffering.

Furthermore, researchers who study compassion at work quantitatively should use methods designed specifically to examine dyads in organizations (Gooty \& Yammarino 2011, Krasikova \& LeBreton 2012). The use of these kinds of analytic approaches would allow for the modeling of withindyad interdependence and take into account the mutual influences between the focal actor and the sufferer over time. The use of these methods not only would allow for better alignment between theory and method but also would open up new theoretical questions about how compassion-based interactions at work are distinct from-versus similar to-other kinds of dyadic interactions (e.g., mentoring, helping, social supporting).

\section{PRACTICAL IMPLICATIONS}

Given the important benefits of compassion at work discussed above, organizations and individuals within them must reduce organizational barriers to noticing coworkers' suffering, feeling that suffering, and acting to alleviate the suffering, as well as strengthen the contextual enablers of compassion. See Table 2 for a summary.

\section{Implications for Individuals}

Individuals, as focal actors, can cultivate skills to aid in the unfolding of compassionate responding in the workplace. One possibility involves deliberately opening oneself to noticing and accepting that "there is always pain in the room" (a phrase our colleague Peter Frost frequently used). A second option would be to cultivate mindfulness as a mechanism for improving the noticing and feeling of the pain of others at work (Atkins \& Parker 2012). Research suggests that meditation is also a powerful means for increasing people's responses to others' suffering (Condon et al. 2013). Individuals may also craft their jobs so that their roles provide them with resources to feel, make sense of, and respond to workplace suffering (Wrzesniewski \& Dutton 2001). For example, people could consult with those more experienced in dealing with particular kinds of suffering and seek their advice about how to act compassionately.

As sufferers or focal actors, individuals need to keep in mind that compassion is a relational process. Each party's actions, or lack thereof, affect the other. For instance, although it may not always be possible, appropriate, or easy, sufferers may play an active role in facilitating com-passion from others by being explicit about the causes and extent of their suffering as well as by communicating their own ideas about how others might help relieve it. Focal actors may do their part by trying to make sufferers feel safe and comfortable engaging in such dialogues. Both parties should be mindful, however, that opening up in this way may be more difficult if the relationship they share is not close or if there are power differentials between them. In such cases, a helpful step before actions aimed directly at minimizing suffering might be to work on finding common ground and developing a closer connection. By taking an open and cooperative approach, sufferers and focal actors can reduce 
uncertainty about what has happened and what can be done about it, and both parties may feel greater self-efficacy with regard to alleviating suffering.

Table 2 Practical implications of research on compassion at work for individuals and organizations

\begin{tabular}{|c|c|}
\hline Individuals & Organizations \\
\hline $\begin{array}{l}\text { Individuals can cultivate skills to facilitate compassionate responding by: } \\
\text { Deliberately acknowledging and accepting the pervasive presence } \\
\text { of suffering in the workplace } \\
\text { n Cultivating mindfulness and practicing meditation } \\
\text { Crafting one's job to ensure that the role provides resources to } \\
\text { feel, make sense of, and respond to workplace suffering } \\
\text { The process takes place in a relational context, which has three } \\
\text { implications: } \\
\text { Sufferers can be more explicit about suffering and needs } \\
\text { Focal actors can make efforts to create psychological safety for } \\
\text { expressing suffering } \\
\text { Both sufferers and focal actors can work to strengthen the quality } \\
\text { of connections }\end{array}$ & $\begin{array}{l}\text { Leaders are in a unique position to promote workplace } \\
\text { compassion through: } \\
\text { Treating individuals as whole people who carry } \\
\text { emotions into the workplace and display them } \\
\text { Encouraging permeable work and life boundaries } \\
\text { Facilitating high-quality relationships among } \\
\text { employees } \\
\text { Implementing practices that support compassion-for } \\
\text { example, by using selection and socialization } \\
\text { practices, employee support practices, or other } \\
\text { practices that foster noticing, feeling, sensemaking, } \\
\text { and acting in ways that foster compassion }\end{array}$ \\
\hline
\end{tabular}

\section{Implications for Organizations}

As we have seen, organizations greatly impact the unfolding of compassion in the workplace, which leads directly to implications for managerial practice. Leaders should strive to exhibit behavior in line with promoting compassion: treating individuals as whole people who carry emotions into the workplace and display them (Dutton et al. 2006), encouraging permeable work and life boundaries (Lilius et al. 2011), and facilitating high-quality relationships among employees (Dutton et al. 2006). Alternatively, leaders could work to implement practices that support compassion-for example, by using selection and socialization practices, employee support practices, or other practices that foster noticing, feeling, sense making, and acting in ways that foster compassion.

\section{CONCLUDING THOUGHTS}

Studying compassion at work brings researchers face-to-face with the dark (suffering) and the light (compassion) sides of human experiences at work. The research is both heartbreaking (Whiteman 2010) and heartwarming (Dutton \& Workman 2011), thus requiring an emotional readiness for working with these ideas and an intellectual motivation to work through the variety of conceptual and empirical challenges associated with a new research domain. We hope that this review of the theoretical and empirical work to date motivates new impactful research that not only fills holes but also opens new frontiers of insight about this critical relational process that is interwoven in the fabric of the lives of people at work.

\section{DISCLOSURE STATEMENT}

The authors are not aware of any affiliations, memberships, funding, or financial holdings that might be perceived as affecting the objectivity of this review. 


\section{ACKNOWLEDGMENTS}

A special thanks to Sue Ashford, Oana Branzei, Jason Kanov, Jacoba Lilius, Sally Maidis, and Frederick Morgeson for their comments on a previous draft of this review.

\section{LITERATURE CITED}

Adler NJ, Hansen H. 2012. Daring to care: scholarship that supports the courage of our convictions. J. Manag. Inq. 21(2):128-39

Ashford SJ, Lee C, Bobko P. 1989. Content, causes, and consequences of job insecurity: a theory-based measure and substantive test. Acad. Manag. J. 32(4):803-29

Ashforth BE, Kreiner GE, Fugate M. 2000. All in a day's work: boundaries and micro role transitions. Acad. Manag. Rev. 25:472-91

Atkins PWB, Parker SK. 2012. Understanding individual compassion in organizations: the role of appraisals and psychological flexibility. Acad. Manag. Rev. 37(4):524-46

Baker WE, Faulkner RR. 1991. Role as resource in the Hollywood film industry. Am. J. Sociol. 97:279-309

Batson CD. 1987. Prosocial motivation: Is it ever truly altruistic? Adv. Exp. Soc. Psychol. 20:65-122

Batson CD. 1994. Why act for the public good? Four answers. Personal. Soc. Psychol. Bull. 20(5):603-10

Batson CD, Batson JG, Griffitt CA, Barrientos S, Brandt JR, et al. 1989. Negative-state relief and the empathy- altruism hypothesis. /. Personal. Soc. Psychol. 56(6):922-33

Batson CD, Early S, Salvarani G. 1997. Perspective taking: imagining how another feels versus imagining how you would feel. Personal. Soc. Psychol. Bull. 23(7):751-58

Batson CD, Eklund JH, Chermok VL, Hoyt JL, Ortiz BG. 2007. An additional antecedent of empathic concern: valuing the welfare of the person in need. /. Personal. Soc. Psychol. 93(I):65-74

Batson CD, Shaw LL. 1991. Evidence for altruism: toward a pluralism of prosocial motives. Psychol. Inq. 2(2):107-22

Beehr TA, Bowling NA, Bennett MM. 2010. Occupational stress and failures of social support: when helping hurts./. Occup. Health Psychol. 15(I):45-59

Bento RF. 1994. When the show must go on: disenfranchised grief in organizations./. Manag. Psychol. 9(6):35-44

Berdahl JL, Martorana P. 2006. Effects of power on emotion and expression during a controversial group discussion. Eur. J. Soc. Psychol. 36(4):497-509

Blau PM. 1964. Exchange and Power in Social Life. Edison, NJ: Transaction Publishers. 1st ed.

Bond FW, Hayes SC, Barnes-Holmes D. 2006. Psychological flexibility, ACT, and organizational behavior. J. Organ. Behav. Manag. 26(I-2):25-54

Bowlby J. 1983. Attachment and Loss, Vol. 1: Attachment. New York: Basic Books. 2nd ed. 
Boyatzis RE, McKee A. 2005. Resonant Leadership: Renewing Yourself and Connecting with Others Through Mindfulness, Hope, and Compassion. Boston: Harvard Bus. School Press

Brody H. 1992. Assisted death-a compassionate response to a medical failure. N. Engl. J. Med. 327(19):1384-88

Broverman IK, Vogel SR, Broverman DM, Clarkson FE, Rosenkrantz PS. 1972. Sex-role stereotypes: a current appraisal./. Soc. Issues 28(2):59-78

Brown SL, Brown RM, Penner LA. 2011. Moving Beyond Self-Interest: Perspectives from Evolutionary Biology, Neuroscience, and the Social Sciences. New York: Oxford Univ. Press

Cassell EJ. 1999. Diagnosing suffering: a perspective. Ann. Intern. Med. 131:531-34

Chamberlain K, Zika S. 1990. The minor events approach to stress: support for the use of daily hassles. Br.\}. Psychol. 81:469-81

Chen E, Matthews KA. 2001. Cognitive appraisal biases: an approach to understanding the relation between socioeconomic status and cardiovascular reactivity in children. Ann. Behav. Med. 23(2): 10111

Chiaburu D, Harrison D. 2008. Do peers make the place? Conceptual synthesis and meta-analysis of coworker effects on perceptions, attitudes, OCBs, and performance./. Appl. Psychol. 93(5):1082-103

Clark C. 1987. Sympathy biography and sympathy margin. Am. J. Sociol. 93:290-321 Condon P, Desbordes G, Miller WB, DeSteno D. 2013. Meditation increases compassionate responses to suffering. Psychol. Sci. 24:2125-27

Condon P, DeSteno D. 2011. Compassion for one reduces punishment for another. J. Exp. Soc. Psychol. 47(3):698-701

Cote S, Kraus MW, Cheng BH, Oveis C, van der Lowe I, et al. 2011. Social power facilitates the effect of prosocial orientation on empathic accuracy./. Personal. Soc. Psychol. 101(2):217-32

Crocker J, Canevello A. 2008. Creating and undermining social support in communal relationships: the role of compassionate and self-image goals./. Personal. Soc. Psychol. 95(3):555-75

Cutcliffe JR. 2002. Understanding and working with bereavement. Mental Health Pract. 6:30-37

De Waal F. 2009. Primates and Philosophers: How Morality Evolved. Princeton, NJ: Princeton Univ. Press

Dickert S, Slovic P. 2009. Attentional mechanisms in the generation of sympathy. Judgm. Decis. Mak. 4(4):297-306

Doka KJ, ed. 1989. Disenfranchised Grief: Recognizing Hidden Sorrow. Lexington, MA: Lexington Books

Driver M. 2007. Meaning and suffering in organizations. J. Organ. Change Manag. 20:611-32

Dutton JE. 2003. Breathing life into organizational studies. J. Manag. Inq. 12(1):5-19

Dutton JE, Debebe G, Wrzesniewski A. 2014. Being valued and devalued at work: a social valuing perspective. In Qualitative Organizational Research: Best Papers from the Davis Conference on 
Qualitative Research, Vol. 3, ed. K Elsbach, B Betchky. Charlotte, NC: Inf. Age. In press Dutton JE, Frost PJ, Worline MC, Lilius JM, Kanov JM. 2002. Leading in times of trauma. Harv. Bus. Rev. 80(1):54-61

Dutton JE, Heaphy ED. 2003. The power of high-quality connections. In Positive Organizational Scholarship: Foundations of a New Discipline, ed. KS Cameron, JE Dutton, RE Quinn, pp. 263-78. San Francisco: Berrett-Koehler

Dutton JE, Lilius JM, Kanov JM. 2007. The transformative potential of compassion at work. In Handbook of Transformative Cooperation: New Designs and Dynamics, ed. SK Piderit, RE Fry, DL Cooperrider, pp. 107-26. Stanford, CA: Stanford Univ. Press

Dutton JE, Ragins BR, eds. 2007. Exploring Positive Relationships at Work: Building a Theoretical and Research Foundation. Mahwah, NJ: Lawrence Erlbaum Assoc.

Dutton JE, Workman KM. 2011. Commentary on 'Why compassion counts!': compassion as a generative force. J. Manag. Inq. 20(4):402-6

Dutton JE, Worline MC, Frost PJ, Lilius JM. 2006. Explaining compassion organizing. Adm. Sci. Q. 51(1 ):59-96

Erickson JM, Pugh WM, Gunderson KE. 1972. Status congruency as a predictor of job satisfaction and life stress. J. Appl. Psychol. 56:523-25

Ferrin DL, Dirks KT, Shah PP. 2006. Direct and indirect effects of third-party relationships on interpersonal trust./. Appl. Psychol. 91(4):870-83

Ferris GR, Liden RC, Munyon TP, Summers JK, Basik KJ, Buckley MR. 2009. Relationships at work: toward a multidimensional conceptualization of dyadic work relationships. J. Manag. 35(6):1379-403

Figley CR, ed. 1995. Compassion Fatigue: Coping with Secondary Traumatic Stress Disorder in Those Who Treat the Traumatized. New York: Routledge

Fineman S. 2000. Emotion in Organizations. London: Sage. 2nd ed.

Fiske ST. 1993. Controlling other people: the impact of power on stereotyping. Am. Psychol. 48(6)=62128

Fredrickson BL. 2013. Love 2.0: How Our Supreme Emotion Affects Everything We Feel, Think, Do, and Become. New York: Hudson Street Frost PJ. 1999. Why compassion counts! J. Manag. Inq. 8(2):127-33

Frost PJ. 2003. Toxic Emotions at Work: How Compassionate Managers Handle Pain and Conflict. Boston: Harvard Bus. School Press

Frost PJ, Dutton JE, Maitlis S, Lilius JM, Kanov JM, Worline MC. 2006. Seeing organizations differently: three lenses on compassion. In The Sage Handbook of Organization Studies, ed. SR Clegg, C Hardy, TB Lawrence, WR Nord, pp. 843-66. London: Sage. 2nd ed.

Frost PJ, Dutton JE, Worline MC, Wilson A. 2000. Narratives of compassion in organizations. See Fineman 2000, pp. 25-45 
Frost PJ, Robinson SL. 1999. The toxic handler: organizational hero-and casualty. Harv. Bus. Rev. 1999(July-Aug.):96-106

Galinsky AD, Magee JC, Inesi ME, Gruenfeld DH. 2006. Power and perspectives not taken. Psychol. Sci. 17(12):1068-74

Gersick CJG, Dutton JE, Bartunek JM. 2000. Learning from academia: the importance of relationships in professional life. Acad. Manag. J. 43(6):1026-44

Gittell JH, Douglass A. 2012. Relational bureaucracy: structuring reciprocal relationships into roles. Acad. Manag. Rev. 37(4):709-33

Goetz JL, Keltner D, Simon-Thomas E. 2010. Compassion: an evolutionary analysis and empirical review. Psychol. Bull. 136(3):351-74

Goodrum S. 2008. When the management of grief becomes everyday life: the aftermath of murder. Symb. Interact. 31:420-41

Gooty J, Yammarino FJ. 2011. Dyads in organizational research: conceptual issues and multilevel analyses. Organ. Res. Methods 14(3):456-83

Grant AM, Dutton JE, Rosso BD. 2008. Giving commitment: employee support programs and the prosocial sense making process. Acad. Manag. J. 51(5):898-918

Grant AM, Mayer DM. 2009. Good soldiers and good actors: prosocial and impression management motives as interactive predictors of affiliative citizenship behaviors. ]. Appl. Psychol. 94(4):900-12

Haidt J. 2002. The moral emotions. In Handbook of Affective Sciences, ed. RJ Davidson, KR Scherer, HH Goldsmith, pp. 852-70. New York: Oxford Univ. Press. 1st ed.

Halifax J. 2011. The precious necessity of compassion. J. Pain Symptom Manag. 41(I):146-53 Hazen MA. 2008. Grief and the workplace. Acad. Manag. Perspect. 22(3):78-86

Heaphy ED, Dutton JE. 2008. Positive social interactions and the human body at work: linking organizations and physiology. Acad. Manag. Rev. 33(1):13 7-62

Hochschild A. 1983. The Managed Heart: Commercialization of Human Feelings. Berkeley: Univ. Calif. Press

Horowitz LM, Krasnoperova EN, Tatar DG, Hansen MB, Person EA, et al. 2001. The way to console may depend on the goal: experimental studies of social support. ]. Exp. Soc. Psychol. 37(1):49-61 lacovides A, Fountoulakis KN, Kaprinis S, Kaprinis G. 2003. The relationship between job stress, burnout and clinical depression. J. Affect. Disord. 75:209-21

Ickes W, Stinson L, Bissonnette V, Garcia S. 1990. Naturalistic social cognition: empathic accuracy in mixed- sex dyads. J. Personal. Soc. Psychol. 59(4):730-42

Jeong H-S, Brower RS. 2008. Extending the present understanding of organizational sense making: three stages and three contexts. Adm. Soc. 40(3):223-52 
John OP, Naumann LP, Soto CJ. 2008. Paradigm shift to the integrative Big Five trait taxonomy: history, measurement, and conceptual issues. In Handbook of Personality: Theory and Research, ed. OP John, RW Robins, LA Pervin, pp. 114-58. New York: Guilford. 3rd ed.

Johnson PR, Indvik J. 1996. Stress and workplace violence: It takes two to tango. ]. Manag. Psychol. 11 (6):18-27

Kahn RL, Wolfe DM, Quinn RP, Snoek JD, Rosenthal RA. 1964. Organizational Stress: Studies in Role Conflict and Ambiguity. New York: Wiley

Kahn WA. 1993. Caring for the caregivers: patterns of organizational caregiving. Adm. Sci. Q. 38:539-63

Kahn WA. 1998. Relational systems at work. Res. Organ. Behav. 20:39-76

Kanov JM, Maitlis S, Worline MC, Dutton JE, Frost PJ, Lilius JM. 2004. Compassion in organizational life. Am. Behav. Sci. 47(6):808-27

Katz D, Kahn RL. 1978. The Social Psychology of Organizations. New York: Wiley. 2nd ed.

Keltner D. 2009. Bom to Be Good: The Science of a Meaningful Life. New York: W.W. Norton Keltner D, Gruenfeld DH, Anderson C. 2003. Power, approach, and inhibition. Psychol. Rev. 110(2):265-84

Kitayama S, Markus HR. 2000. The pursuit of happiness and the realization of sympathy: cultural patterns of self, social relations, and well-being. In Culture and Subjective Well-Being, ed. E Diener, EM Suh, pp. 113-61. Cambridge, MA: MIT Press

Krasikova DV, LeBreton JM. 2012. Just the two of us: misalignment of theory and methods in examining dyadic phenomena. J. Appl. Psychol. 97(4):739-57

Kraus MW, Cote S, Keltner D. 2010. Social class, contextualism, and empathic accuracy. Psychol. Sci. 21(II):1716-23

Kraus MW, Piff PK, Mendoza-Denton R, Rheinschmidt ML, Keltner D. 2012. Social class, solipsism, and contextualism: how the rich are different from the poor. Psychol. Rev. 119(3):546-72

Lawrence TB, Maitlis S. 2012. Care and possibility: enacting an ethic of care through narrative practice. Acad. Manag. Rev. 37(4):641-63

Lazarus RS. 1991. Emotion and Adaptation. New York: Oxford Univ. Press

Leavy RL. 1983. Social support and psychological disorder: a review. J. Community Psychol. 11(1):3-21

Lee D. 2000. An analysis of workplace bullying in the UK. Pers. Rev. 29:593-610 Levenson RW, Ruef AM. 1992. Empathy: a physiological substrate. J. Personal. Soc. Psychol. 63(2):234-46

Lilius JM. 2012. Recovery at work: understanding the restorative side of "depleting" client interactions. Acad. Manag. Rev. 37(4):569-88

Lilius JM, Kanov JM, Dutton JE, Worline MC, Maitlis S. 2012. Compassion revealed: what we know about compassion at work (and where we still need to know more). In The Handbook of Positive Organizational Scholarship, ed. KS Cameron, G Spreitzer, pp. 273-87. New York: Oxford Univ. Press 
Lilius JM, Worline MC, Dutton JE, Kanov JM, Maitlis S. 2011. Understanding compassion capability. Hum. Relat. 64(7):873-99

Lilius JM, Worline MC, Maitlis S, Kanov JM, Dutton JE, Frost PJ. 2008. The contours and consequences of compassion at work. ]. Organ. Behav. 29(2):193-218

Lois J. 2001. Managing emotions, intimacy, and relationships in a volunteer search and rescue group. J. Contemp. Ethnogr. 30:131-79

Lopez SH. 2006. Emotional labor and organized emotional care: conceptualizing nursing home care work. Work Occup. 33(2):133-60

Madden LT, Duchon D, Madden TM, Plowman DA. 2012. Emergent organizational capacity for compassion. Acad. Manag. Rev. 37(4):689-708

Manns ML, Little S. 2011. Grief and compassion in the workplace. J. Behav. Stud. Bus. Vol. 4. http://www. aabri.com/manuscripts/11858.pdf

McClelland LE. 2012. From compassion to satisfaction: examining the relationship between routines that facilitate compassion and quality of service. PhD Thesis, Emory Univ., Atlanta

Melwani S, Mueller JS, Overbeck JR. 2012. Looking down: the influence of contempt and compassion on emergent leadership categorizations. J. Appl. Psychol. 97(6):1171-85

Mercadillo RE, Diaz JL, Pasaye EH, Barrios FA. 2011. Perception of suffering and compassion experience: brain gender disparities. Brain Cogn. 76(1):5-14

Mikulincer M, Gillath O, Halevy V, Avihou N, Avidan S, Eshkoli N. 2001. Attachment theory and reactions to others' needs: evidence that activation of the sense of attachment security promotes empathic responses./. Personal. Soc. Psychol. 81(6):1205-24

Mikulincer M, Shaver PR. 2005. Attachment security, compassion, and altruism. Curr. Dir. Psychol. Sci. 14(1):34-38

Miller GA. 1956. The magical number seven, plus or minus two: some limits on our capacity for processing information. Psychol. Rev. 63(2):81-97

Miller KI. 2002. The experience of emotion in the workplace: professing in the midst of tragedy. Manag. Commun. Q. 15(4):571-600

Miller KI. 2007. Compassionate communication in the workplace: exploring processes of noticing, connecting, and responding./. Appl. Commun. Res. 35(3):223-45

Mishra AK, Mishra KE, Spreitzer GM. 2009. Downsizing the company without downsizing morale. MIT Sloan Manag. Rev. 50(3):39-44

Molinsky AL, Grant AM, Margolis JD. 2012. The bedside manner of homo economicus: how and why priming an economic schema reduces compassion. Organ. Behav. Hum. Decis. Process. 119(1):27-37 
Nussbaum M. 1996. Compassion: the basic social emotion. Soc. Philos. Policy 13:27-58 O'Donohoe S, Turley D. 2006. Compassion at the counter: service providers and bereaved consumers. Hum. Relat. 59(10):1429-48

O'Reilly CA, Chatman JA. 1996. Culture as social control: corporations, cults, and commitment. Res. Organ. Behav. 18:157-200

Orlikowski WJ. 1992. The duality of technology: rethinking the concept of technology in organizations. Organ. Sci. 3(3):398^127

Oveis C, Horberg EJ, Keltner D. 2010. Compassion, pride, and social intuitions of self-other similarity. /. Personal. Soc. Psychol. 98(4):618-30

Powley EH. 2009. Reclaiming resilience and safety: resilience activation in the critical period of crisis. Hum. Relat. 62(9):1289-326

Rice RW, Frone MR, McFarlin DB. 1992. Work-nonwork conflict and the perceived quality of life. J. Organ. Behav. 13:155-68

Rosch PJ. 2001. The quandary of job stress compensation. Health Stress 2001\{3):1-4 Rynes SL, Bartunek JM, Dutton JE, Margolis JD. 2012. Care and compassion through an organizational lens: opening up new possibilities. Acad. Manag. Rev. 37(4):503-23

Schein EH. 1985. Organizational culture and leadership: a dynamic view. Hum. Resour. Manag. 24(3):370-75

Shiota MN, Keltner D, John OP. 2006. Positive emotion dispositions differentially associated with Big Five personality and attachment style./. Posit. Psychol. 1(2):61-71

Simpson AV, Clegg S, Pina e Cunha M. 2013. Expressing compassion in the face of crisis: organizational practices in the aftermath of the Brisbane floods of 2011. J. Conting. Crisis Manag. 21(2):115-24

Smircich L. 1983. Concepts of culture and organizational analysis. Adm. Sci. Q. 28(3):339-58

Stamm BH. 2002. Measuring compassion satisfaction as well as fatigue: developmental history of the compassion satisfaction and fatigue test. In Treating Compassion Fatigue, ed. CR Figley, pp. 107-19. New York: Brunner-Routledge

Stein AJ, Winokuer HR. 1989. Monday mourning: managing employee grief. See Doka 1989, pp. 91-102

Stellar JE, Manzo VM, Kraus MW, Keltner D. 2012. Class and compassion: socioeconomic factors predict responses to suffering. Emotion 12(3):449-59 Stewart MR, Kleiner BH. 1997. How to curb workplace violence. Facilities 15(1-2):5-11

Sullivan D, Landau MJ, Kay AC, Rothschild ZK. 2012. Collectivism and the meaning of suffering. /. Personal. Soc. Psychol. 103(6):1023-39

Taylor JR, Van Every EJ. 2000. The Emergent Organization: Communication as Its Site and Surface. Mahwah, NJ: Lawrence Erlbaum Assoc. 
Taylor SE, Klein LC, Lewis BP, Gruenewald TL, Gurung RAR, Updegraff JA. 2000. Biobehavioral re-sponses to stress in females: tend-and-befriend, not fight-or-flight. Psychol. Rev. 107(3):411-29

Trice HM, Beyer JM. 1993. The Cultures of Work Organizations. Englewood Cliffs, NJ: Prentice Hall Tsui A. 2013. On compassion in scholarship: Why should we care? Acad. Manag. Rev. In press, doi: 10.5465/amr.2013.0016

Tyler TR, Lind EA. 1992. A relational model of authority in groups. Adv. Exp. Soc. Psychol. 25:115-91 Valdesolo P, DeSteno D. 2011. Synchrony and the social tuning of compassion. Emotion II(2):262-66 van Kleef GA, Oveis C, van der Lowe I, LuoKogan A, Goetz JL, Keltner D. 2008. Power, distress, and compassion: turning a blind eye to the suffering of others. Psychol. Sci. 19(12):1315-22

Victor B, Stephens C. 1994. The dark side of the new organizational forms: an editorial essay. Organ. Sci. $5: 479-82$

Way D. 2010. Recognizing, relating, and responding: hospice workers and the communication of compassion. PhD Thesis, Ariz. State Univ., Tempe, AZ

Way D, Tracy SJ. 2012. Conceptualizing compassion as recognizing, relating and (re)acting: a qualitative study of compassionate communication at hospice. Commun. Monogr. 79(3):292-315

Weick KE. 2001. Making Sense of the Organization. Oxford, UK: Blackwell

Weick KE. 2012. Organized sense making: a commentary on processes of interpretive work. Hum. Relat. 65(I):141-53

Weick KE, Sutcliffe KM, Obstfeld D. 2005. Organizing and the process of sense making. Organ. Sci. 16(4):409-21

Whetten DA. 2001. What matters most. Acad. Manag. Rev. 26(2):175-78

Whiteman G. 2010. Management studies that break your heart. J. Manag. Inq. 19(4):328-37

Williams M, Dutton JE. 1999. Corrosive political climates: the heavy toll of negative political behavior in organizations. In Pressing Problems in Modern Organizations (That Keep Us Up at Night): Transforming Agendas for Research and Practice, ed. RE Quinn, RM O’Neill, L St. Clair, pp. 3-30. New York: Am. Manag. Assoc.

Worline MC, Boik S. 2006. Leadership lessons from Sarah: values-based leadership as everyday practice. In Leading with Values: Positivity, Virtue, and High Performance, ed. ED Hess, KS Cameron, pp. 108-31. Cambridge, UK: Cambridge Univ. Press

Wrzesniewski A, Dutton JE. 2001. Crafting a job: revisioning employees as active crafters of their work. Acad. Manag. Rev. 26(2):179-201

Zaslow J. 2002. New index aims to calculate the annual cost of despair. The Wall Street Journal, Nov. 20, pp. DI, D12 
Zenteno-Hidalgo A, Geddes D. 2012. A model of compassionate responses to anger expression. In Research on Emotion in Organizations, Vol. 8: Experiencing and Managing Emotions in the Workplace, ed. NM Ashkanasy, CEJ Hartel, WJ Zerbe, pp. 257-77. Bingley, UK: Emerald Group 